Graduate Thesis RePORTS

\title{
SITUAR: A platform for in-situ augmented reality content creation
}

\author{
Fernando Vera, J. Alfredo Sánchez
}

Published: 21 September 2016

\begin{abstract}
We present a work in progress related to an Augmented Reality (AR) platform, which is intended to be used by the end user to create their own stories through multimedia content. Based upon a review of existing tools to create $A R$ scenarios in the context of smart cities, we have developed SituAR, a platform in which the user is able to create AR content using multimedia, storytelling and gamification elements. Our goal is to facilitate the creation of $\mathrm{AR}$ scenarios and to empower users to become authors. We also include social media elements used for users to share, rank, and comment the content created in order to add new information and to facilitate interaction. This paper discusses SituAR and its potential. In addition, we present preliminary prototypes. Finally, this project is aimed to produce an engaging platform for promoting cultural heritage through interactive stories added to POIs by end users.
\end{abstract}

Keywords: Augmented Reality, Point of Interest, Storytelling, User Experience.

\section{Introduction}

Augmented Reality is an area of research that aims to enhance the real world by overlaying digital information on top of it. AR applications enrich the perception of the context and it is a new way to interact with information. Augmented reality can help to supply information in a context with limited information and enhance user experience. The creation of augmented reality content can potentiate the integration of social media. The user could create in- situ points of interest, add new information to the real world from their experience and share it with other people. The user would stop being a consumer and would become a prosumer. A relevant application of AR is related with its social use. By combining social networks and AR interfaces, there is a potential to satisfy user needs to find people and share experiences and information with friends. In order to give added value to content, SituAR, a model to create AR with multimedia elements, it will include storytelling in which the user is more involved in the interaction and contributing to the point of interest by creating a story that can evolve and other users can contribute to it. The

Vera, F., Sánchez, JA.

Laboratory of Interactive and Cooperative Technologies

Universidad de las Américas Puebla

Cholula, Puebla, México

Email: fernando.verapo@udlap.mx, alfredo.sanchez@udlap.mx purpose of the narrative is to achieve a more detailed content, therefore, end users such as experts, visitors, and managers of cultural sites can add the components of the story, the characters, multimedia elements, and gamification mechanics. It is noteworthy that a user who wants to interact with this content in a given context can have a more immersive experience through games, trivia and role selection in order to have a better appreciation and a different perspective of the POI they are visiting. In historical places, the creation of stories with augmented reality and the social media elements are important, that is, the user can share their experience, giving their opinions and describing points of interest. In this sense, we are exploring new ways of interaction.

One of the objectives is the dissemination and preservation of cultural heritage, by encouraging the visitors in historic places, where they use SituAR and have a better understanding about the context and the surroundings.

\section{Related work}

Our approach with AR is based on points of interest (POI's). One of the main concerns is how to represent the information with tags. In [1] floating labels using GPS coordinates are described as one of the most frequently techniques used. We can also use geolocation and markers, the first one use the GPS of the mobile device and the marker identifies a space that display the content in real time [7]. The use of these markers is supported by platforms such as Wikitude, Layar, Junaio, Vuforia and ARtoolkit, and are useful to prototype augmented reality [8].

Recently there have been projects that merge augmented reality with social media, which is called AR 2.0 [4], and is considered as a trend because the impact of social media. There are devices that enable to deploy AR, such as Google Glasses. But mobile devices such as smartphones and tablets are more popular tools to use and experiment with augmented reality applications [3].

Annotation is a technique that associates information with places, objects or people. Hansen created a taxonomy for all kinds of system annotations [4].

Langlotz et al. introduce the concept of augmented reality 2.0 , it which refers to a trend of making users content creators and not only consumers, one of the main characteristics of the Web 2.0 [6]. FitzGerald created user generated content (UGC) for location- based learning, where users actively create content and publish it on the web and location awareness [2]. In order to engage users to create quality content that add value to SituAR, we propose transmedia storytelling, which is a new way of telling 
stories across multiple platforms creating an immersive experience for the viewer. The purpose being to not only reach a wider audience by expanding the target market, but to expand the narrative itself [9]. Coordinated storytelling across multiple platforms offers users a new, more compelling perspective of the characters' use [5]. To the storytelling is added a level of participation, interaction and collaboration of the audience [10]. There are commercial applications with augmented reality related to POIs such as Layar, Here City Lens, and Wikitude, which allow users to visualize information related with POIs and upload images or create comments, but users cannot create annotations in the real world. Therefore, users are not able to create stories. It is noteworthy that commercial AR applications show POI's and can take user from one point (location) to another. Nevertheless, they are not connected with a social network that can contribute with comments, rate the places and add multimedia elements of a POI's such as videos, images or audio. The problem with these applications is that the information is uploaded before use or they are desktop-based.

\section{Research objective}

Advance knowledge in understanding of AR by proposing a model in order to generate in-situ AR content. Moreover, SituAR is focused on the exploration of storytelling elements to provide the user the tools to share their experience by creating stories in varied contexts with multimedia elements.

\section{Methods}

The $\mathrm{PhD}$ project is focused on Hansen approach on presenting annotations where the user and object are co-located. The annotations created by the end user are deployed on the physical object using AR technology.

The development of this work is divided into six stages. Figure 1 illustrates the sequence of phases that will be followed during this research:
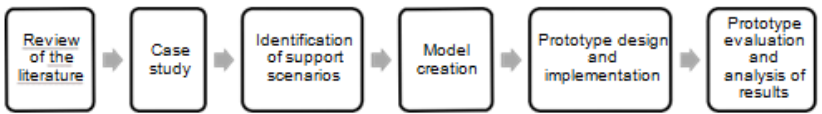

Figure 1. Research methodology

\section{Current results}

After reviewing the augmented reality state of the art, a qualitative study was conducted in order to learn user perception in augmented reality contexts. The purpose of the context exploration was to understand the characteristics and the problems that users have in points of interest and their perception of the acceptance of technologies like mobile device and AR.

SituAR consists of 3 major components for the creation and visualization of Augmented Reality content:

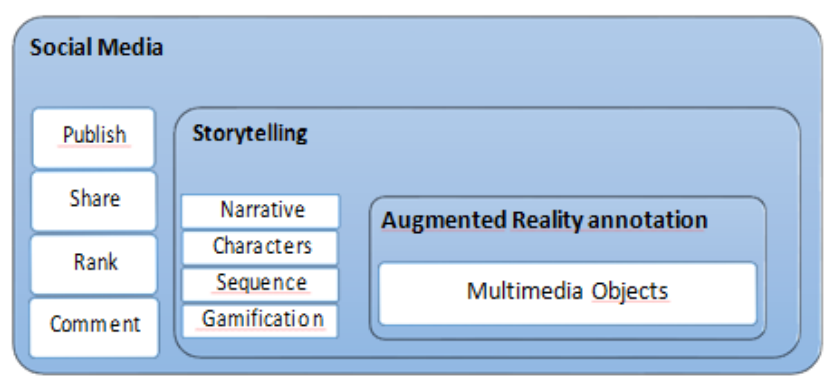

Figure 2. SituAR components
We propose a structure to create stories. Narrative, characters, sequence and gamification allow users to tell a story including the main characters of the story. Also, the sequence is needed to have different locations and scenarios. Finally, we add the gamification component where users can gain points when they create stories and interact with others. These stories will use AR annotations to provide a new way of interaction to the users. Moreover, SituAR gives the tools to create the stories and AR annotations. We have on top of the model the users that are represented by social media. The users of the platform will be able to publish, share, rank and comment stories. SituAR will be the AR authoring tool that helps the user to design new experiences and it proposes these elements:

\section{SITUAR $=\{$ Users, Stories, Augmented Reality, Multimedia $\}$ Users $=\{$ Publish, Share, Rank, Comment $\}$ \\ Storytelling $=\{$ Narrative, Sequence, Characters, $[$ Gamification $]\}$ \\ Augmented reality $=\{A R$ annotation, Multimedia $\}$ \\ Multimedia $=\{$ Text, Audio, Video, Pictures, 3 D Objects $\}$}

In order to validate the SituAR model, we created a high-end prototype to represent the components of the model (Figure 3). $\mathrm{AR}$ annotations are visualized as multimedia objects such as text, image and video. Also, the user can interact with stories.

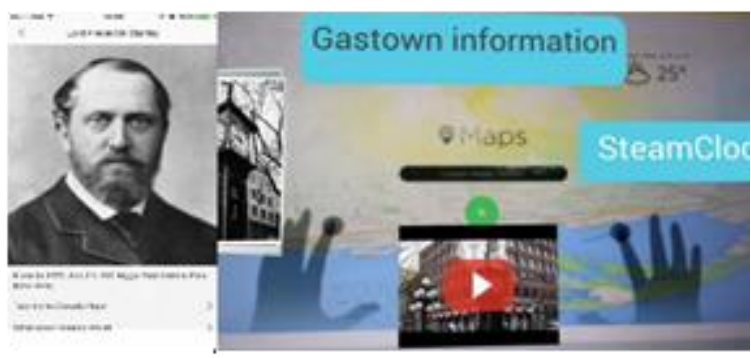

Figure 3. Interaction with SituAR elements

The interaction is carried out through geolocation using mobile devices and the augmented reality is deployed by AR markers. Next, we will conduct usability studies and a focus group of situAR

\section{Potential conclusions}

The creation of augmented reality content by the end user can promote the integration of social media. Users could create new stories in POI's, add new information to the real world from their experience and share it with other people. Also, users can stop being mere consumer and can become prosumers. They can design new experiences for other users with gamification mechanics in order to engage people. Storytelling allows users to participate in an active way when they interact with POI's. SituAR contributes in the active participation of the user in the merge of AR, social media, gamification, multimedia and storytelling to promote cultural heritage. The integration of gamification mechanics with augmented reality in the stories could motivates people to use this platform as a new way to interact in POIs and improve their experience.

\section{With what I need help with?}

User experience methods to evaluate mobile systems and feedback to improve SituAR model.

\section{References}

[1] Choi, J., Jang, B. and Kim, G. J. 2011. Organizing and presenting geospatial tags in location-based augmented 
reality. Personal and Ubiquitous Computing, vol. 15, no. 6, pp. 641-647.

[2] FitzGerald, E. 2012. Creating user-generated content for location-based learning: an authoring framework. Journal of Computer Assisted Learning.

[3] Gervautz, M. and Schmalstieg, D. 2012. Anywhere Interfaces Using Handheld Augmented Reality. Computer, pp. 26-31.

[4] Hansen., F.A. 2006. Ubiquitous annotation systems. In proceedings of seventh conference on hypertext and hypermedia, HYPERTEXT '06 page 121, New York, New York, USA. ACM Press.

[5] Jenkins, H. (2014). Transmedia Storytelling and Entertainment: An annotated syllabus in Continuum: Journal of Media \& Cultural Studies, 24, 6. Communication \& Mass Media Complete, EBSCOhost, viewed, 26, 943-958.

[6] Langlotz, T., Mooslechner, S., Zollmann, S., Degendorfer, C., Reitmayr, G. \& Schmalstieg, D. 2012. Sketching up the world: in situ authoring for mobile augmented reality. Personal and ubiquitous computing, 16(6), 623-630.

[7] Madden, L. 2011. Professional augmented reality browsers for smartphones: programming for junaio, layar and wikitude. John Wiley \& Sons.

[8] Mullen, T. 2011. Prototyping augmented reality. John Wiley \& Sons. [9] Phillips, A. (2012). A creator's guide to transmedia storytelling: How to captivate and engage gradaudiences across multiple platforms. McGraw Hill Professional.

[9] Pratten, R. (2012). Transmedia Storytelling: Getting Started. Workbook Project.

[10] Schmalstieg, D., Langlotz, T. \& Billinghurst, M. 2011. Augmented Reality 2.0. In Virtual Realities (pp. 13-37). Springer Vienna 